\title{
Enhanced Mechanical and Thermal Properties of Modified Oil Palm Fiber-Reinforced Polypropylene Composite via Multi-Objective Optimization of In Situ Silica Sol-Gel Synthesis
}

\author{
Nasrullah Mat Rozi ${ }^{1}$, Hamidah Abdul Hamid ${ }^{1}$ (D), Md. Sohrab Hossain ${ }^{2, *(D)}$, Nor Afifah Khalil ${ }^{1}$ (D), \\ Ahmad Naim Ahmad Yahaya ${ }^{1}$ (D) Ahmad Noor Syimir Fizal ${ }^{1}$, , Mohd Yusoff Haris ${ }^{3}$, Norkhairi Ahmad ${ }^{4}(\mathbb{D}$ \\ and Muzafar Zulkifli ${ }^{1,3, * \mathbb{D}}$
}

1 Green Chemistry and Sustainability Cluster, Branch Campus Malaysian Institute of Chemical and Bioengineering Technology, University Kuala Lumpur, Taboh Naning, 78000 Alor Gajah, Melaka, Malaysia; nasrullah5157@gmail.com (N.M.R.); hamidah.abdhamid@unikl.edu.my (H.A.H.); norafifah@unikl.edu.my (N.A.K.); ahmadnaim@unikl.edu.my (A.N.A.Y.); syimir.fizal@s.unikl.edu.my (A.N.S.F.)

2 School of Industrial Technology, Universiti Sains Malaysia, 11800 USM, Penang, Malaysia;

3 Aerocomposite Cluster, Branch Campus Malaysian Institute of Aviation Technology, University Kuala Lumpur, 43900 Sepang, Selangor, Malaysia; mohdyusoff@unikl.edu.my

check for updates

Citation: Mat Rozi, N.; Hamid, H.A.; Hossain, M.S.; Khalil, N.A.; Ahmad Yahaya, A.N.; Syimir Fizal, A.N.; Haris, M.Y.; Ahmad, N.; Zulkifli, M Enhanced Mechanical and Thermal Properties of Modified Oil Palm Fiber-Reinforced Polypropylene Composite via Multi-Objective Optimization of In Situ Silica Sol-Gel Synthesis. Polymers 2021, 13, 3338. https://doi.org/10.3390/ polym13193338

Academic Editor: Vincenzo Fiore

Received: 19 July 2021

Accepted: 15 September 2021

Published: 29 September 2021

Publisher's Note: MDPI stays neutral with regard to jurisdictional claims in published maps and institutional affiliations.

Copyright: (c) 2021 by the authors. Licensee MDPI, Basel, Switzerland. This article is an open access article distributed under the terms and conditions of the Creative Commons Attribution (CC BY) license (https:// creativecommons.org/licenses/by/ $4.0 /)$.
4 Industrial Linkages Section, Branch Campus Malaysian France Institute, Universiti Kuala Lumpur, 43650 Bandar Baru Bangi, Selangor, Malaysia; norkhairi@unikl.edu.my

* Correspondence: sohrab@usm.my (M.S.H.); muzafar@unikl.edu.my (M.Z.); Tel.: +60-46535206 (M.S.H.); +60-65512085 (M.Z.); Fax: +60-46533678 (M.S.H.); +60-65512001 (M.Z.)

Abstract: A multi-objective optimization of in situ sol-gel process was conducted in preparing oil palm fiber-reinforced polypropylene (OPF-PP) composite for an enhancement of mechanical and thermal properties. Tetraethyl orthosilicate (TEOS) and butylamine were used as precursors and catalysts for the sol-gel process. The face-centered central composite design (FCCD) experiments coupled with response surface methodology (RSM) has been utilized to optimize in situ silica sol-gel process. The optimization process showed that the drying time after the in-situ silica sol-gel process was the most influential factor on silica content, while the molar ratio of TEOS to water gave the most significant effect on silica residue. The maximum silica content of $34.1 \%$ and the silica residue of $35.9 \%$ were achieved under optimum conditions of $21.3 \mathrm{~h}$ soaking time, 50 min drying time, $\mathrm{pH}$ value of 9.26, and 1:4 molar ratio of TEOS to water. The untreated oil palm fiber (OPF) and silica sol-gel modified OPF $\left(\mathrm{SiO}_{2}-\mathrm{OPF}\right)$ were used as the reinforcing fibers, with $\mathrm{PP}$ as a matrix and maleic anhydride grafted polypropylene (MAgPP) as a compatibilizer for the fiber-reinforced PP matrix $\left(\mathrm{SiO}_{2}\right.$-OPF-PP-MAgPP) composites preparation. The mechanical and thermal properties of OPF-PP, $\mathrm{SiO}_{2}$-OPF-PP, $\mathrm{SiO}_{2}$-OPF-PP-MAgPP composites, and pure PP were determined. It was found that the OPF-S-PP-MAgPP composite had the highest toughness and stiffness with values of tensile strength, Young's modulus, and elongation at break of $30.9 \mathrm{MPa}, 881.8 \mathrm{MPa}$, and $15.1 \%$, respectively. The thermal properties analyses revealed that the OPF-S-PP-MAgPP exhibited the highest thermally stable inflection point at $477^{\circ} \mathrm{C}$ as compared to pure PP and other composites formulations. The finding of the present study showed that the $\mathrm{SiO}_{2}$-OPF had the potential to use as a reinforcing agent to enhance the thermal-mechanical properties of the composites.

Keywords: oil palm fiber; silica sol-gel; natural fiber reinforced composite; polymeric composite; polypropylene; maleic anhydride grafted polypropylene

\section{Introduction}

Natural fibers are gaining significant attention for their potential in replacing the conventional synthetic fibers for the fiber reinforcement into polymeric composites in terms 
of environmental benefits, high stiffness-to-weight ratio, and relatively inexpensive feed stocks [1-3]. Recently, there is an increasing interest on natural fibers derived from biomass to produce natural fiber-reinforced composites (NFRCs) [4-6]. The structure of biomass consists of rigid crystalline cellulose in a soft amorphous matrix of lignin and hemicellulose, which also contains pectins, waxes, and water-soluble substances [7,8]. Biomass fibers are easily available and serve as low-cost reinforcement materials to the polymeric composites, which could provide a profitable and sustainable solution to the biomass disposal issue. Oil palm fiber (OPF) is one of the major contributors to the global biomass fibers generation, which consists of huge amounts of empty fruit bunches, mesocarp fibers, palm kernel shells, oil palm trunks, and oil palm fronds [9-11]. It is estimated that worldwide generation of oil palm fibers would be 149 million ton in 2020, which is twofold of a total mass of extracted palm oil [12]. Moreover, the OPF which contains 48 to $65 \%$ cellulose has specific modulus and high specific strength comparable to glass fibers [13-15].

There are some processing issues of NFRCs, such as hygroscopic properties of natural fiber that leads to the dimensional instability of NFRCs, surface fiber degradation at temperature above $200^{\circ} \mathrm{C}$, and the complexity of composites machining [1,16-18]. Nevertheless, the limitations of reinforcing the natural fibers into polymer matrices could be improved by a pre-processing step, such as modifications of the polymer matrices and surfaces of natural fiber via physical or chemical technologies [19-21]. The use of thermoplastic polymers such as polypropylene (PP) and polyethylene $[22,23]$ to bind the reinforcing fibers has less difficult processing technique and better design flexibility than thermosetting polymers such as epoxy and phenolic $[15,24]$. The development of OPF-reinforced PP composite has high potential to be used for light-weight automotive industry components, due to its improvement in tensile modulus, flexural strength, and flexural modulus [25]. However, the incompatibility of OPF-PP composite would cause a poor interfacial adhesion between the reinforcing OPF and PP matrix [26]. Hence, an addition of a coupling agent such as maleic anhydride-grafted polypropylene (MAgPP) during a melt blending would improve its impact resistance, stiffness, and dimensional stability $[23,27,28]$. Moreover, the OPF residual oil removal and alkali treatment to eliminate the impurities on their surfaces, result in better adhesion between OPF and the polymer matrix [22].

Furthermore, OPF has leakage concern due to its poor thermal stability, which limits its applications. A formation of gel-like diphasic colloidal solution (sol-gel) is an attractive lowcost technology to enhance the thermal and structural performance of OPF [29]. Tetraethyl orthosilicate (TEOS) is often used in silicon dioxide (silica) sol-gel synthesis due its low toxicity. The utilization of TEOS as a precursor to the sol-gel process has improved the properties of OPF in terms of enhanced mechanical properties, thermal stability, and melting point [30-32]. Moreover, an in situ silica sol-gel has been used as an effective filler to reduce the void content of lignocellulosic fibers, which favor high performance polymeric composites [24,33]. During a complete hydrolysis of TEOS, a network formation of hydrolyzed monomers and siloxane bonds (Si-O-Si) would occur and breaks down to produce silica sol-gel as the main product [34]. A complete in situ synthesis of silica sol-gel could be achieved by using an excess water and/or the use of chemical catalysts such as butylamine, fluoride, and ammonium hydroxide [32,34]. High molar ratio of water to TEOS $(\geq 4)$ would be sufficient to drive toward a complete conversion of silica [35]. Instead, an early stage of partial reversible hydrolysis could occur, leading to alcohol and water condensations to form siloxane bonds (Figure 1).

Studies have been conducted on the synthesis of natural fiber-reinforced thermoplastics composite $[15,19,25]$. However, there are rarely any studies that have been conducted on the synthesis of polymeric composite reinforced with modified OPF with sol-gel silica. Utilization of silica produced via sol-gel process for lignocellulosic fibre in thermoplastics showed that the dispersion of silica nano particle size 10-50 $\mathrm{nm}$ through sol-gel in the matrix shows improvement in the tensile modulus and thermal stability of LDPE-based composites [35]. It is also stated that the sol-gel process improves the dispersion of filler and adhesion to hydrophobic matrix such as polyethylene and reaction speed is controllable. A 
biodegradable composite of PLA/wood flour (WF)/ $\mathrm{SiO}_{2}$ was also developed by utilizing TEOS via the sol-gel process [36]. The composite produces tensile strength improvement of $20 \mathrm{MPa}$ and initial decomposition temperature (IDT) increased with $10 \mathrm{wt}$. \% of silica present in the composite. This increases greatly the thermal stability of the composite. Therefore, in the present study, butylamine and TEOS were used as alkaline catalyst and precursor respectively for in situ silica sol-gel synthesis. The synthesis was optimized by using a response surface methodology combined with face-centered central composite design (FCCD). The optimization of in situ silica sol-gel process is essential as an initial process that enhances the mechanical and thermal properties of OPF-S-PP-MAgPP composite. The comparison of mechanical and thermal properties between the investigated composites was also carried out.

$$
\begin{aligned}
& \mathrm{Si}(\mathrm{OR})_{4}+2 \mathrm{H}_{2} \mathrm{O} \stackrel{\text { complete hydrolysis }}{\longrightarrow} \mathrm{SiO}_{2}+2 \mathrm{ROH} \\
& \mathrm{Si}(\mathrm{OR})_{4}+\mathrm{H}_{2} \mathrm{O} \underset{\text { esterification }}{\stackrel{\text { hydrolysis }}{\rightleftharpoons}} \mathrm{HO}-\mathrm{Si}(\mathrm{OR})_{3}+\mathrm{ROH}
\end{aligned}
$$

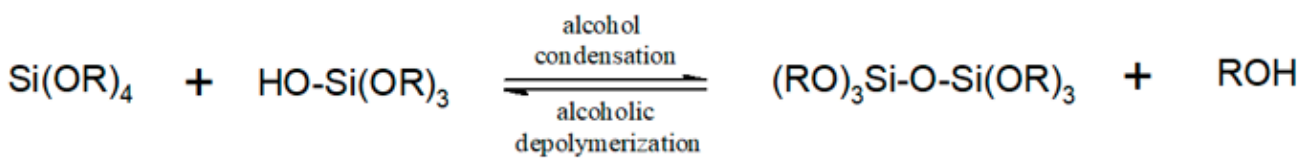

$$
\begin{aligned}
& \mathrm{Si}(\mathrm{OR})_{4}+\mathrm{HO}-\mathrm{Si}(\mathrm{OR})_{3} \underset{\begin{array}{c}
\text { water } \\
\text { hydrolytic } \\
\text { depolymerization }
\end{array}}{\frac{\text { condensation }}{2}}(\mathrm{RO})_{3} \mathrm{Si}-\mathrm{O}-\mathrm{Si}(\mathrm{OR})_{3}+\mathrm{H}_{2} \mathrm{O}
\end{aligned}
$$

Figure 1. Hydrolysis, series of condensations and reverse reactions of silicon alkoxide.

\section{Materials and Methods}

\subsection{Materials}

The OPF was supplied by Kilang Sawit Meru Sdn. Bhd. (Meru Oil Palm Plant, Private Limited) (Shah Alam, Malaysia) and the PP (PP456J, extrusion grade) was purchased from Lyondell Basell Industries N. V. (Rotterdam, The Netherlands). Tetraethyl orthosilicate (TEOS), butylamine, and hydrochloric acid $(\mathrm{HCl})$ were acquired from Merck (Shah Alam, Malaysia) while maleic anhydride-grafted polypropylene (MAgPP) was purchased from Lotte Chemical Titan (M) Sdn. Bhd. (Johor Bahru, Malaysia).

\subsection{Design of Experiment and Optimization of In Situ Silica Sol-Gel Synthesis}

Beforehand, OPF was dried in a conventional air flow oven (Memmert Drying Oven ULE 500, Schwabach, Germany) at a temperature of $105^{\circ} \mathrm{C}$ for $48 \mathrm{~h}$ until a moisture content of less than $5 \%$ was achieved. The dried OPF was then ground and sieved to obtain the desired range of particle sizes between 100 and $300 \mu \mathrm{m}$. Response surface methodology combined with FCCD was used to conduct an optimization study of an in situ silica sol-gel synthesis on OPF. Design Expert (Version 11: Minneapolis, MN, USA) was used to run a matrix of 31 experimental runs and to analyze the results. The ranges of four independent variables (factors) for the silica sol-gel process are soaking time, drying time, $\mathrm{pH}$ value and molar ratio of TEOS to water, as tabulated in Table 1. 
Table 1. Factors and ranges for in situ silica sol-gel silica synthesis on oil palm fiber.

\begin{tabular}{ccccc}
\hline \multirow{2}{*}{ Factor } & Symbol & \multicolumn{3}{c}{ Levels } \\
\cline { 3 - 5 } & & Low (-1) & Medium (0) & High (+1) \\
\hline $\mathrm{pH}$ & $\mathrm{A}$ & 7 & 9 & 11 \\
Soaking time (h) & $\mathrm{B}$ & 18 & 22 & 26 \\
Drying time (min) & $\mathrm{C}$ & 30 & 75 & 120 \\
Molar ratio of & $\mathrm{D}$ & $1: 1$ & $1: 2.5$ & $1 .: 4$ \\
TEOS/water & & & & \\
\hline
\end{tabular}

The samples of OPF were first soaked into butylamine solution with $2.5 \%$ purity and a $\mathrm{pH}$ value of 11 for $24 \mathrm{~h}$, to clean the external surface and enlarge the pores of OPF samples, so that the silica sol-gel could penetrate inside the OPF effectively. The samples were then oven-dried for $24 \mathrm{~h}$ at $110^{\circ} \mathrm{C}$. The dried OPF samples were soaked into TEOS at specified molar ratio of TEOS to water. The treated OPF was soaked again in the butylamine solution for $1 \mathrm{~h}$, at varied $\mathrm{pH}$ values and final soaking times. The $\mathrm{pH}$ value of solution was controlled and stabilized by using a titration of butylamine solution and $\mathrm{HCl}$ solution. Then, the OPF samples were oven-dried at varied drying times. The investigated responses are the silica content determined by using Equation (1) and the amount of silica residue from the thermogravimetric analysis.

$$
\text { Silica content }(S C \%)=\frac{w 2-w 1}{w 1} \times 100
$$

where $w 1$ is a weight of OPF in $g$ unit and $w 2$ is a weight of modified silica sol-gel OPF (OPF-S) in $g$ unit. Meanwhile, the amount of silica residue from thermogravimetric analysis was determined after the silica sol-gel processing was completed. The schematic diagram for the production of OPF and OPF-S conducted through sol-gel process is presented in Figure 2. The experiments were conducted in triplicate and the results are represented as the mean values from the triplicate experimental runs.
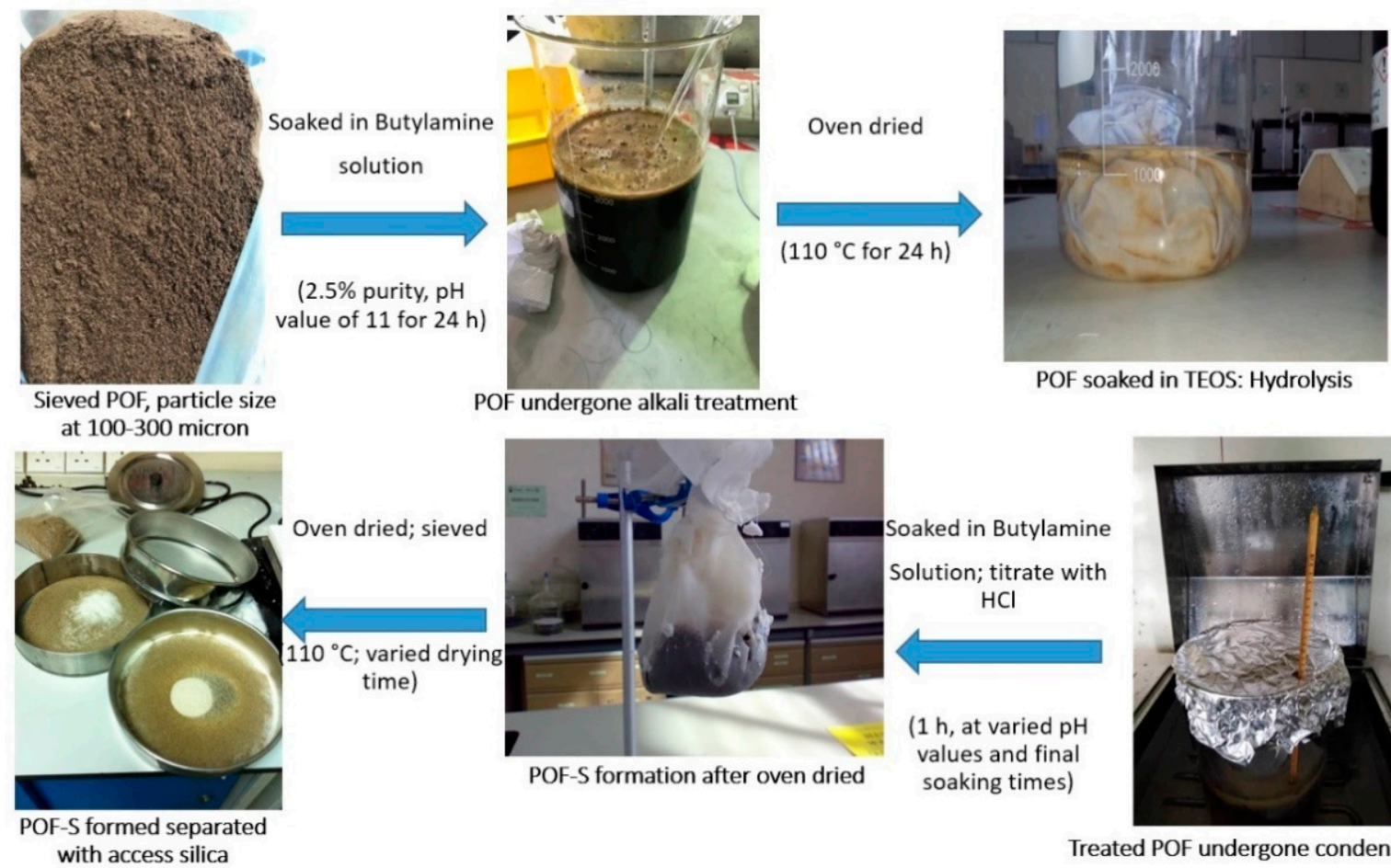

POF soaked in TEOS: Hydrolysis

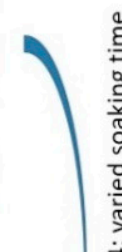

Figure 2. Schematic diagram of the production of OPF and OPF-S conducted through sol-gel process. 


\subsection{Preparation of Natural Fiber Reinforced Composites}

The silica sol-gel modified-OPF based composite was prepared by a melt blend process using a twin-screw extruder (Model Haake ${ }^{\mathrm{TM}}$ P 300, Thermo Fisher Scientific, Waltham, MA, USA) by mixing $30 \%$ of untreated OPF and $70 \%$ of PP. Then, the blended sample was crushed into smaller pellets with a cruncher to provide larger contact areas. Then, the final stage was carried out by using an injection molding machine (Wittmann Battenfeld 60 tonne, Vienna, Austria). The preparation steps were repeated by using silica sol-gel modified-OPF and PP-MAgPP to fabricate silica sol-gel modified-OPF-PP and silica sol-gel modified-OPF-PP-MAgPP composites. The compounding formulation of composites are depicted in Table 2.

Table 2. Compounding formulation of composites.

\begin{tabular}{ccccc}
\hline Sample & $\begin{array}{c}\text { Polypropylene, } \\
\text { PP (wt } \%)\end{array}$ & $\begin{array}{c}\text { Oil Palm Fiber, } \\
\text { OPF (wt \%) }\end{array}$ & $\begin{array}{c}\text { Silica Sol-Gel } \\
\text { Modified-OPF (wt\%) }\end{array}$ & $\begin{array}{c}\text { MAgPP Coupling } \\
\text { Agent (wt \%) }\end{array}$ \\
\hline OPF-PP & 70 & 30 & - & - \\
$\mathrm{SiO}_{2}$-OPF-PP & 70 & - & 30 & - \\
$\mathrm{SiO}_{2}$-OPF-PP-MAgPP & 70 & - & 30 & 10 \\
\hline
\end{tabular}

\subsection{Mechanical Characterization}

Tensile and flexural tests of 7 specimens from each type of composite were performed according to ASTM D3039 and ASTM D790, respectively using Lloyd universal testing machine (honglin, Shandong, China)with a strain rate of $50 \mathrm{~mm} / \mathrm{min}$ at a load of $1 \mathrm{kN}$. Meanwhile, an impact test for 7 specimens from each type of composite was conducted using Ray-Ran Pendulum Impact Tester (Selangor, Malaysia) according to ISO 179, with a load of $1.189 \mathrm{~kg}$ and velocity rate at $2.9 \mathrm{~m} \mathrm{~s}^{-1}$. All samples were conditioned for $24 \mathrm{~h}$ at $23 \pm 2{ }^{\circ} \mathrm{C}$ and $50 \pm 5 \%$ relative humidity (RH) before the tests were carried out.

\subsection{Termogravimetric Analysis (TGA)}

The thermal degradation of the composite samples was tested using ASTM E1131 and analyzed using Mettler Toledo TGA machine (Selangor, Malaysia), with complete nitrogen and air burning conditions. The samples were weighed at 7-15 mg at constant heat rate of $10{ }^{\circ} \mathrm{C} / \mathrm{min}$ to $800{ }^{\circ} \mathrm{C}$ with nitrogen and 800 to $1000{ }^{\circ} \mathrm{C}$ with air purge at $50 \mathrm{~mL} / \mathrm{min}$. The curve and maximum inflection point were analyzed to determine the thermal stability of the samples.

\subsection{Surface Morphology Analyses}

The broken impact testings of the composites were carried out using ultra highresolution scanning electron microscope (FESEM) Hitachi-SU 8000 (Tokyo, Japan). The analysis studies the morphology of the composite, the content of silica on the surface and inside the OPF, and determines the size of the void inside of the OPF. Platinum was used to coat the samples to make them more conductive. The analysis was then supplemented with elemental analysis (EDX). The size of the void is determined by using Image J software (Tokyo, Japan). The samples were first coated with a platinum coating to make them more conductive. An elemental analysis at the end was also vital in determining the percentage of components involved in the measured area for identification purposes. About 50 measurements were recorded for each condition used for the SEM images representation.

\section{Results and Discussion}

\subsection{Multi-Objective Optimization of In Situ Silica Sol-Gel Synthesis}

The experimental sequence of in situ silica sol-gel synthesis on OPF was randomized to minimize the experimental runs and effects of extraneous factors. The actual design of experiments (DOE) and results of both responses, which were silica content and silica residue from TGA are presented in Table 3. 
Table 3. Central composite design of experiments for in situ silica sol-gel synthesis on oil palm fiber.

\begin{tabular}{|c|c|c|c|c|c|c|c|c|}
\hline \multirow{3}{*}{ Run } & \multirow{3}{*}{$\mathbf{A}$} & \multirow{3}{*}{ B } & \multirow{3}{*}{$\mathrm{C}$} & \multirow{3}{*}{ D } & \multicolumn{4}{|c|}{ Response } \\
\hline & & & & & \multicolumn{2}{|c|}{ SC (\%) } & \multicolumn{2}{|c|}{ SR (\%) } \\
\hline & & & & & Actual & Predicted & Actual & Predicted \\
\hline 1 & 7 & 18 & 30 & $1: 1$ & 6.78 & 4.23 & 9.28 & 10.76 \\
\hline 2 & 11 & 18 & 30 & $1: 1$ & 7.97 & 8.67 & 13.06 & 12.04 \\
\hline 3 & 7 & 26 & 30 & $1: 1$ & 8.93 & 12.25 & 17.98 & 17.99 \\
\hline 4 & 11 & 26 & 30 & $1: 1$ & 10.17 & 11.59 & 18.35 & 19.20 \\
\hline 5 & 7 & 18 & 120 & $1: 1$ & 11.78 & 13.84 & 15.49 & 16.28 \\
\hline 6 & 11 & 18 & 120 & $1: 1$ & 18.66 & 19.97 & 17.37 & 17.87 \\
\hline 7 & 7 & 26 & 120 & $1: 1$ & 21.3 & 20.38 & 25.64 & 24.94 \\
\hline 8 & 11 & 26 & 120 & $1: 1$ & 22.43 & 20.41 & 25.37 & 26.45 \\
\hline 9 & 7 & 18 & 30 & $1: 4$ & 22.43 & 25.10 & 32.78 & 31.23 \\
\hline 10 & 11 & 18 & 30 & $1: 4$ & 31.72 & 31.47 & 26.95 & 29.13 \\
\hline 11 & 7 & 26 & 30 & $1: 4$ & 32.17 & 29.69 & 18.63 & 19.61 \\
\hline 12 & 11 & 26 & 30 & $1: 4$ & 31.38 & 29.97 & 18.68 & 17.43 \\
\hline 13 & 7 & 18 & 120 & $1: 4$ & 15.92 & 13.33 & 26.02 & 26.65 \\
\hline 14 & 11 & 18 & 120 & $1: 4$ & 23.06 & 20.39 & 25.33 & 24.85 \\
\hline 15 & 7 & 26 & 120 & $1: 4$ & 15.5 & 15.45 & 15.89 & 16.45 \\
\hline 16 & 11 & 26 & 120 & $1: 4$ & 14.04 & 16.42 & 14.57 & 14.57 \\
\hline 17 & 7 & 22 & 75 & $1: 2.5$ & 11.3 & 12.84 & 18.07 & 15.88 \\
\hline 18 & 11 & 22 & 75 & $1: 2.5$ & 15.5 & 16.04 & 17.46 & 15.59 \\
\hline 19 & 9 & 18 & 75 & $1: 2.5$ & 20.22 & 22.55 & 35.59 & 33.06 \\
\hline 20 & 9 & 26 & 75 & $1: 2.5$ & 25.33 & 25.08 & 33.07 & 31.54 \\
\hline 21 & 9 & 22 & 30 & $1: 2.5$ & 37.13 & 36.70 & 34.28 & 32.60 \\
\hline 22 & 9 & 22 & 120 & $1: 2.5$ & 32.72 & 35.23 & 36.31 & 33.93 \\
\hline 23 & 9 & 22 & 75 & $1: 1$ & 28.91 & 26.58 & 36.18 & 33.19 \\
\hline 24 & 9 & 22 & 75 & $1: 4$ & 31.11 & 35.52 & 38.57 & 37.49 \\
\hline 25 & 9 & 22 & 75 & $1: 2.5$ & 31.21 & 29.00 & 32.85 & 32.10 \\
\hline 26 & 9 & 22 & 75 & $1: 2.5$ & 28.75 & 29.00 & 30.66 & 32.10 \\
\hline 27 & 9 & 22 & 75 & $1: 2.5$ & 25.50 & 29.00 & 28.59 & 32.10 \\
\hline 28 & 9 & 22 & 75 & $1: 2.5$ & 29.67 & 29.00 & 27.85 & 32.10 \\
\hline 29 & 9 & 22 & 75 & $1: 2.5$ & 32.54 & 29.00 & 31.28 & 32.10 \\
\hline 30 & 9 & 22 & 75 & $1: 2.5$ & 32.59 & 29.00 & 29.18 & 32.10 \\
\hline 31 & 9 & 22 & 75 & $1: 2.5$ & 30.69 & 29.00 & 31.86 & 32.10 \\
\hline
\end{tabular}

These results were fitted in quadratic polynomial models by applying multiple regression analysis:

$\mathrm{SC}(\%)=-485.1+70.26 \mathrm{~A}+17.06 \mathrm{~B}-0.265 \mathrm{C}+8.03 \mathrm{D}-0.1905 \mathrm{AB}+0.00192 \mathrm{AC}+0.078 \mathrm{AD}-0.00344 \mathrm{BC}-$

$0.184 \mathrm{BD}-0.0829 \mathrm{CD}-3.645 \mathrm{~A}^{2}-0.325 \mathrm{~B}^{2}+0.003429 \mathrm{C}^{2}+0.902 \mathrm{D} 2$

$\mathrm{SR}(\%)=332.1+74.09 \mathrm{~A}+0.99 \mathrm{~B}-0.032 \mathrm{C}+16.78 \mathrm{D}-0.0024 \mathrm{AB}+0.00085 \mathrm{AC}-0.282 \mathrm{AD}+0.00198 \mathrm{BC}-$

$0.786 \mathrm{BD}-0.03744 \mathrm{CD}-4.082 \mathrm{~A}^{2}+0.0149 \mathrm{~B}^{2}+0.000594 \mathrm{C}^{2}+1.459 \mathrm{D}^{2}$ 
where the responses, which are SC (\%) and SR (\%) represent silica content, silica residue from TGA result after the completion of silica sol-gel synthesis (\%) respectively. Meanwhile, $\mathrm{A}, \mathrm{B}, \mathrm{C}$, and $\mathrm{D}$ denote four investigated independent variables, which are $\mathrm{pH}$ value, soaking time (h), drying time ( $\mathrm{min}$ ), and molar ratio of TEOS to water, respectively.

The model represented by Equation (2) infers that an increase in silica content is due to increases in $\mathrm{pH}$ value and soaking time, while reductions in drying time and molar ratio of TEOS to water decreases the silica formation. On the other hand, based on Equation (3), an increase in $\mathrm{pH}$ value and reductions in molar ratio of TEOS to water, soaking and drying times would increase the silica residue from TGA. The analysis of variance (ANOVA) results for both silica content and silica residue are shown in Tables 4 and 5, respectively. Overall, the probability values ( $p$-values) of less than 0.05 , imply that the regression model was statistically significant for predicting both silica content and silica residue and therefore the models are utilized to elucidate all independent variables precisely. Besides, regression coefficient $\left(R^{2}\right)$ values for percentage silica content and silica residue were 0.9354 and 0.9508 , respectively. Wherein, the adjusted regression coefficient $\left(R^{2} A d j\right)$ for the percentage silica content and silica residue were 0.8789 and 0.9077 , respectively. Both $R^{2}$ and $R^{2}$ Adj values reveals that the regression model was good fitted to the experimental data for both silica content and silica residue. The insignificant lack of fit implies that the proposed regression model was sufficient to describe the relationship of independent variables and responses for analyzing both silica content and silica residue.

Table 4. Analysis of variance (ANOVA) for the percentage silica content.

\begin{tabular}{|c|c|c|c|c|c|}
\hline Source & Sum of Squares & $\begin{array}{l}\text { Degree of } \\
\text { Freedom }\end{array}$ & Mean Square & $F$ Value & $p$-Value \\
\hline Model & 2241.06 & 14 & 160.076 & 16.55 & 0.000 \\
\hline A-pH value & 46.41 & 1 & 46.144 & 4.77 & 0.044 \\
\hline B-Soaking time & 28.65 & 1 & 28.652 & 2.96 & 0.104 \\
\hline C-Drying time & 9.78 & 1 & 9.783 & 1.01 & 0.329 \\
\hline D-Molar ratio of TEOS to water & 359.12 & 1 & 359.120 & 37.14 & 0.000 \\
\hline $\mathrm{AB}$ & 37.15 & 1 & 37.149 & 3.84 & 0.068 \\
\hline $\mathrm{AC}$ & 0.48 & 1 & 0.476 & 0.05 & 0.827 \\
\hline $\mathrm{AD}$ & 0.87 & 1 & 0.874 & 0.09 & 0.768 \\
\hline $\mathrm{BC}$ & 6.13 & 1 & 6.126 & 0.63 & 0.438 \\
\hline $\mathrm{BD}$ & 19.54 & 1 & 19.536 & 2.02 & 0.174 \\
\hline $\mathrm{CD}$ & 500.64 & 1 & 500.64 & 51.77 & 0.000 \\
\hline$A^{2}$ & 551.69 & 1 & 551.691 & 57.05 & 0.000 \\
\hline$B^{2}$ & 70.32 & 1 & 70.316 & 7.27 & 0.016 \\
\hline$C^{2}$ & 125.16 & 1 & 125.162 & 12.94 & 0.002 \\
\hline $\mathrm{D}^{2}$ & 10.69 & 0 & 10.691 & 1.11 & 0.309 \\
\hline Residual & 154.73 & 17 & 9.670 & & \\
\hline Lack of fit & 118.10 & 10 & 11.810 & 1.93 & 0.217 \\
\hline Pure error & 36.63 & 8 & 6.105 & & \\
\hline Total & 2395.79 & 31 & & & \\
\hline
\end{tabular}

For the single-factor effect, the $\mathrm{pH}$ and the molar ratio of TEOS to water were statistically significant to the percentage silica content. However, the molar ratio of TEOS to water was the only independent variable that showed a strong significance to predict the silica residue from TGA. When $\mathrm{pH}$ value, soaking time, and the molar ratio of TEOS to water were kept constant at design center-points $(9,22 \mathrm{~h}$, and 1:2.5 respectively), it was observed that the drying time of treated OPF gradually increased the silica content, as illustrated in Figure 3a. However, a reduction of silica content was observed when the sample was dried at more than $60 \mathrm{~min}$. By using oven-drying method, high volumetric shrinkage and highly dense structure of sample could be obtained [37]. Nevertheless, since the alkali-catalyzed hydrolysis of TEOS would yield highly branched silica oligomers [34], it is suggested that 
a prolonged drying time of more than 60 min would produce a smaller pore size of OPF than the silica sol-gel. Hence, the forced removal of the silica network from the voids of OPF would occur. On the other hand, silica content and its residue from TGA results were inversely proportional to the molar ratio of TEOS to water when $\mathrm{pH}$ value, soaking and drying times were maintained at 9, $22 \mathrm{~h}$, and $75 \mathrm{~min}$ (Figure $3 \mathrm{~b}, \mathrm{c}$ ). The highest silica sol-gel formation was achieved at 1:4 molar ratio of TEOS to water, which was evidently sufficient in yielding more silica sol-gel into OPF [38].

Table 5. Analysis of variance (ANOVA) for the percentage silica residue from thermogravimetric analysis.

\begin{tabular}{|c|c|c|c|c|c|}
\hline Source & Sum of Squares & $\begin{array}{l}\text { Degree of } \\
\text { Freedom }\end{array}$ & Mean Square & $F$ Value & $p$-Value \\
\hline Model & 1878.43 & 14 & 134.173 & 22.07 & 0.000 \\
\hline A-pH value & 0.39 & 1 & 0.387 & 0.06 & 0.804 \\
\hline B-Soaking time & 10.41 & 1 & 10.412 & 1.71 & 0.209 \\
\hline C-Drying time & 8.00 & 1 & 8.000 & 1.32 & 0.268 \\
\hline D-Molar ratio of TEOS to water & 83.20 & 1 & 83.205 & 13.69 & 0.002 \\
\hline $\mathrm{AB}$ & 0.01 & 1 & 0.006 & 0.00 & 0.975 \\
\hline $\mathrm{AC}$ & 0.09 & 1 & 0.095 & 0.02 & 0.902 \\
\hline $\mathrm{AD}$ & 11.48 & 1 & 11.475 & 1.89 & 0.188 \\
\hline $\mathrm{BC}$ & 2.02 & 1 & 2.024 & 0.33 & 0.572 \\
\hline $\mathrm{BD}$ & 355.79 & 1 & 355.794 & 58.52 & 0.000 \\
\hline$C D$ & 102.16 & 1 & 102.162 & 16.80 & 0.001 \\
\hline$A^{2}$ & 691.82 & 1 & 691.821 & 113.79 & 0.000 \\
\hline $\mathrm{B}^{2}$ & 0.15 & 1 & 0.147 & 0.02 & 0.879 \\
\hline$C^{2}$ & 3.75 & 1 & 3.754 & 0.62 & 0.443 \\
\hline $\mathrm{D}^{2}$ & 27.97 & & 27.965 & 4.60 & 0.048 \\
\hline Residual & 97.28 & 17 & 6.080 & & \\
\hline Lack of fit & 79.67 & 10 & 7.967 & 2.72 & 0.117 \\
\hline Pure error & 17.60 & 6 & 2.934 & & \\
\hline Total & 1975.71 & 31 & & & \\
\hline
\end{tabular}

Figure 4 shows the response surface plots of main interactive effects of variables on silica sol-gel synthesis from tetraethyl orthosilicate (TEOS). The three-dimensional plot in Figure 4a signifies that the silica content at $\mathrm{pH}$ value of 9 is the most sensitive with changes in molar ratio of TEOS to water. However, a minimal effect of molar ratio of TEOS to water on silica content was observed at lowest and highest $\mathrm{pH}$ values. The hydrolysis of TEOS with an excess water would favor a three-dimensional framework of siloxane bonds formation, which finally leads to the silica sol-gel process [39]. The result suggests that the maximum formation of silica sol-gel could be achieved at the lowest molar ratio of TEOS to water and $\mathrm{pH}$ values between 8 and 10. On the other hand, a moderate effect of soaking time-drying time on silica residue was observed. The highest silica residue was obtained within a middle contour, which fell in the ranges between 60 and 80 min drying times and 20 and $24 \mathrm{~h}$ soaking times. By using a suitable range of soaking time, the hydrogen bonding between butylamine molecules and OPF results in a formation of a thin layer, which could prevent hydroxyl groups of OPF from participating in the hydrolysis of TEOS to silica [40].

The criterion selected in this multi-objective optimization was to maximize the silica content and silica residue from TGA. Design expert software (ver.11) was utilized to optimize the experimental conditions of $\mathrm{pH}$, soaking and drying times, and molar ratio of TEOS to water to maximize the silica content and silica residue. Three independent variables such as $\mathrm{pH}$ value, soaking and drying times were set within the design ranges, while molar ratio of TEOS to water was set at the lowest value as possible. Based on the stipulated goals, the predicted optimum silica content and silica residue within $95 \%$ confidence interval were $37.82 \%$ and $36.49 \%$ respectively. The optimum conditions obtained for the silica sol-gel process were $\mathrm{pH}$ value of $9.26,21.3 \mathrm{~h}$ soaking time, 50 min drying time 
and 1:4 molar ratio of TEOS to water of 1:4, which was based on the highest desirability of 0.796. After experimental triplication and verification, the optimum values silica content and silica residue were obtained at $34.1 \%$ and $35.9 \%$, with their standard deviations of 8.1 and 8.0, respectively.
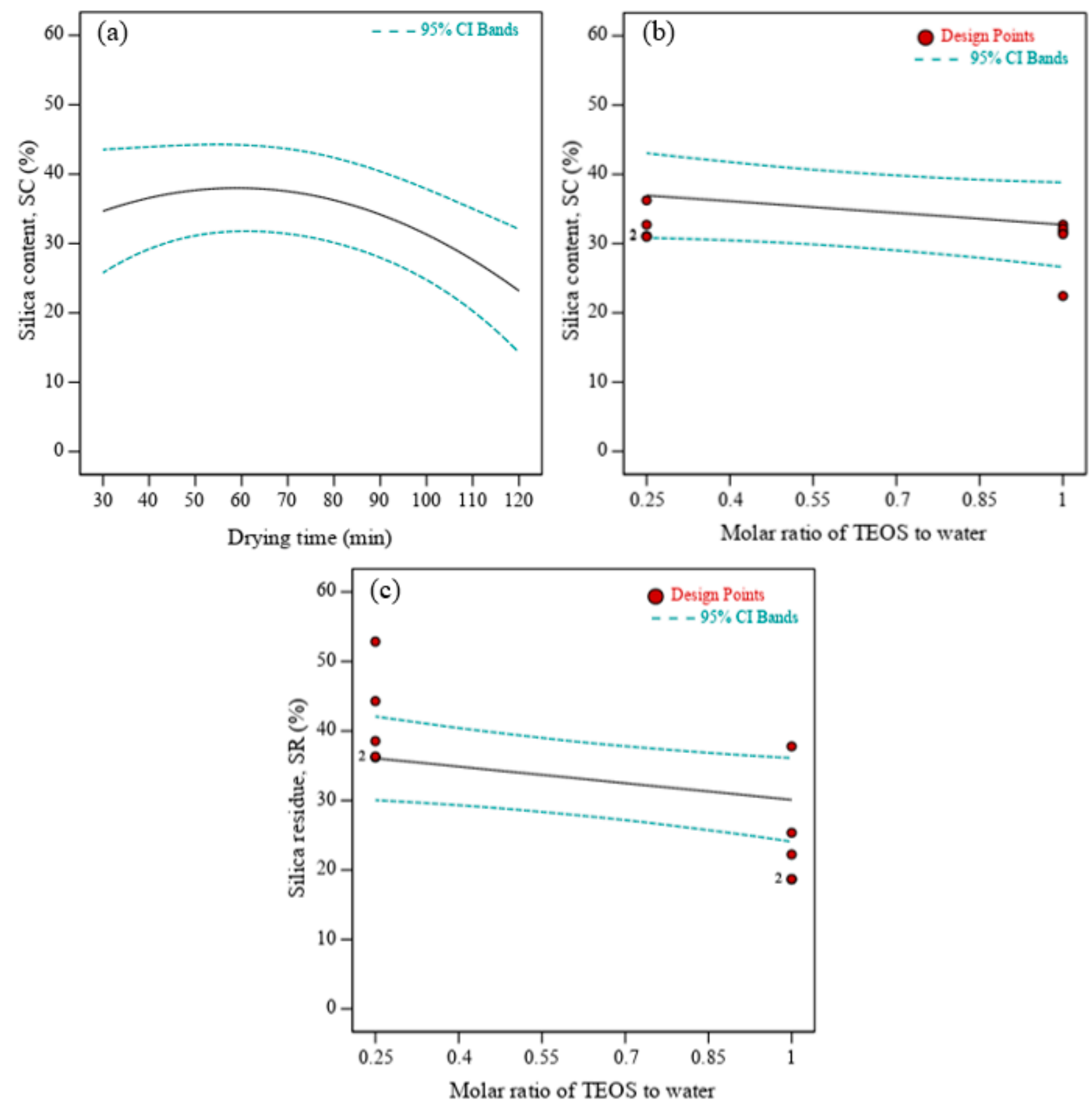

Figure 3. Single-effect of (a) drying time and (b) molar ratio of tetraethyl orthosilicate (TEOS) on silica content and (c) molar ratio of TEOS to water on silica residue.

Silica content was observed in the formed OPF-S with a burn test at $30.2 \mathrm{wt} . \%$. A $1.2 \%$ residue of OPF was found after the completion of burning at $600{ }^{\circ} \mathrm{C}$ for $6 \mathrm{~h}$. The untreated OPF burned off at $98.8 \%$. During the in situ sol-gel silica process modification of OPF, there was a reaction between OPF and butylamine molecules via hydrogen bond, which formed a thin layer. This layer then prevents the hydroxyl groups of OPF from taking part in the reaction with TEOS [40]. This can be visualized in the OFP and OFP-S SEM images, which are shown in Figure 5. The SEM image of the OPF shows the presence of voids and the 
absence of silica on the surface (Figure 5a). The surface of the OPF-S clearly shows the presence of silica particles partially covering the surface and the voids. The range of silica particle size is from 01.5 micron to 0.20 micron in diameter.
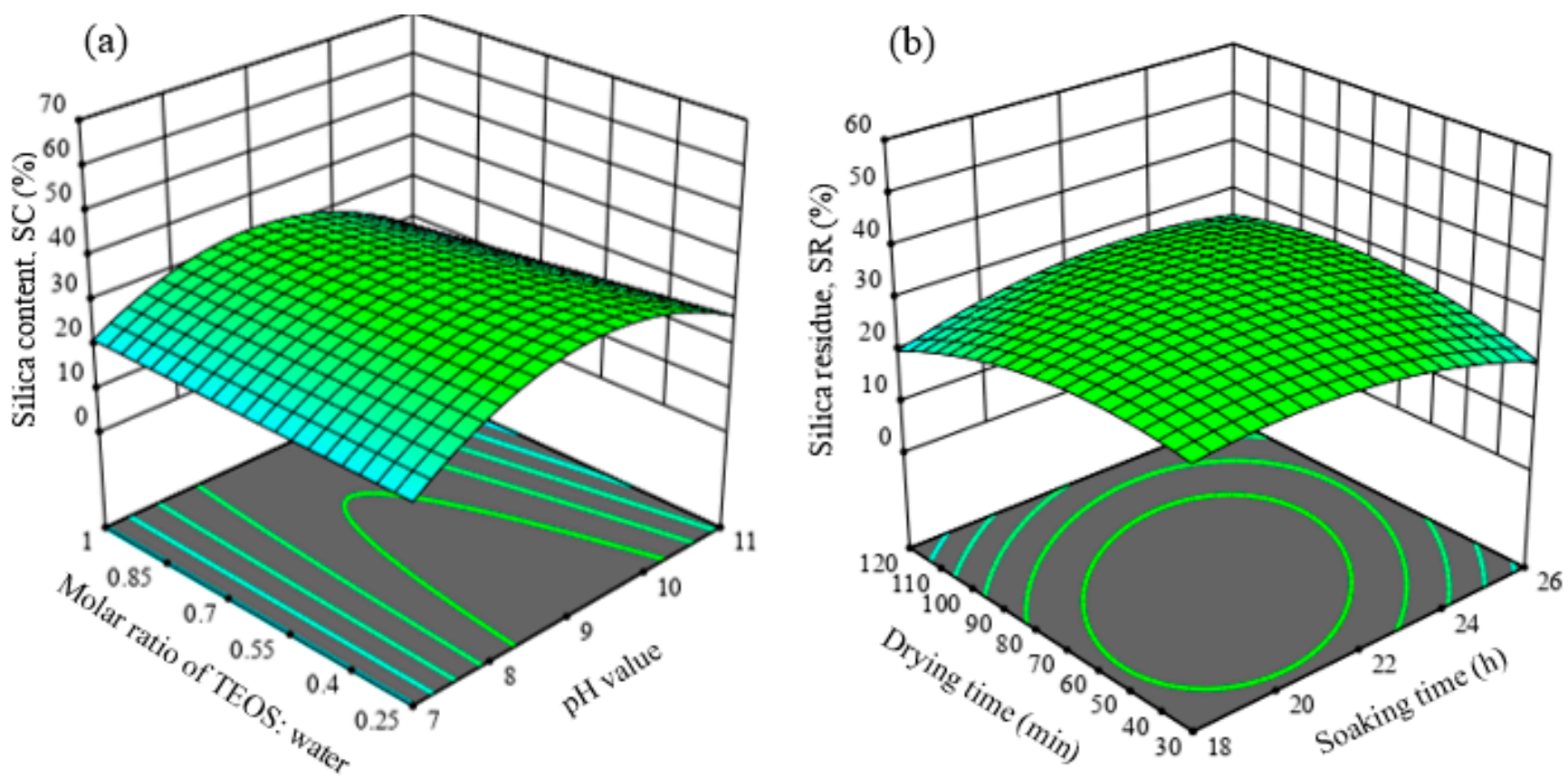

Figure 4. Response surface plots of main interactive effects of variables on silica sol-gel synthesis from tetraethyl orthosilicate (TEOS). (a) Interaction effect between $\mathrm{pH}$ and molar ratio of TEOS to water on silica content (\%); and (b) Interaction effect between drying time and soaking time on silica residue $(\%)$.
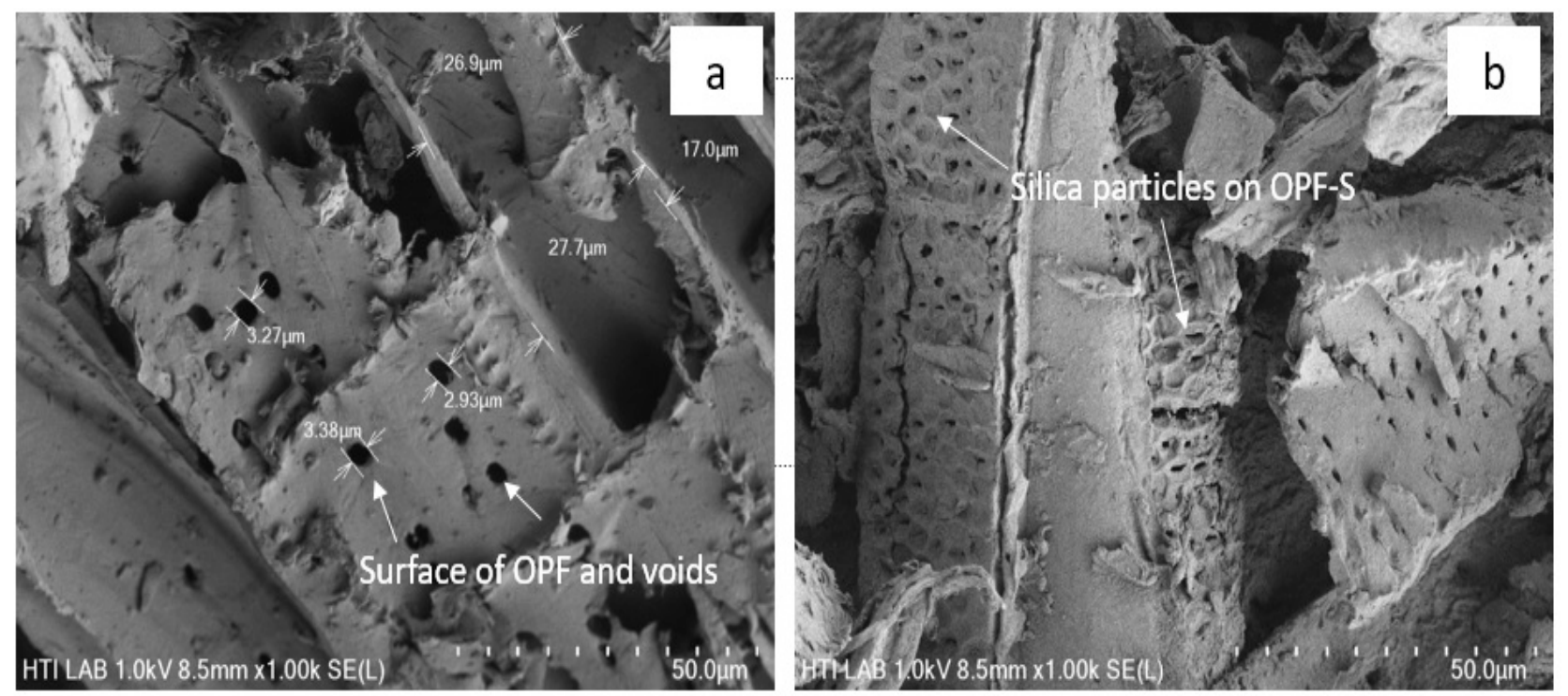

Figure 5. SEM images of the OPF (a) and OPF-S (b).

Figure 6 shows the elemental analysis of OPF and OPF-S with EDX. Both readings were conducted in order to study the void area present on the lignocellulosic fiber. OFP was found with oxygen $(\mathrm{O})$, carbon $(\mathrm{C})$, and platinum $(\mathrm{Pt})$ present. Elemental analysis of OFP-S revealed the presence of $\mathrm{O}, \mathrm{C}, \mathrm{Pt}$ and silica $(\mathrm{Si})$. Si was found with high concentration in the focus area compared to other components. From these findings of EDX and SEM results, the presence of silica in the voids areas of the OPF-S and surrounding surface was proven. 

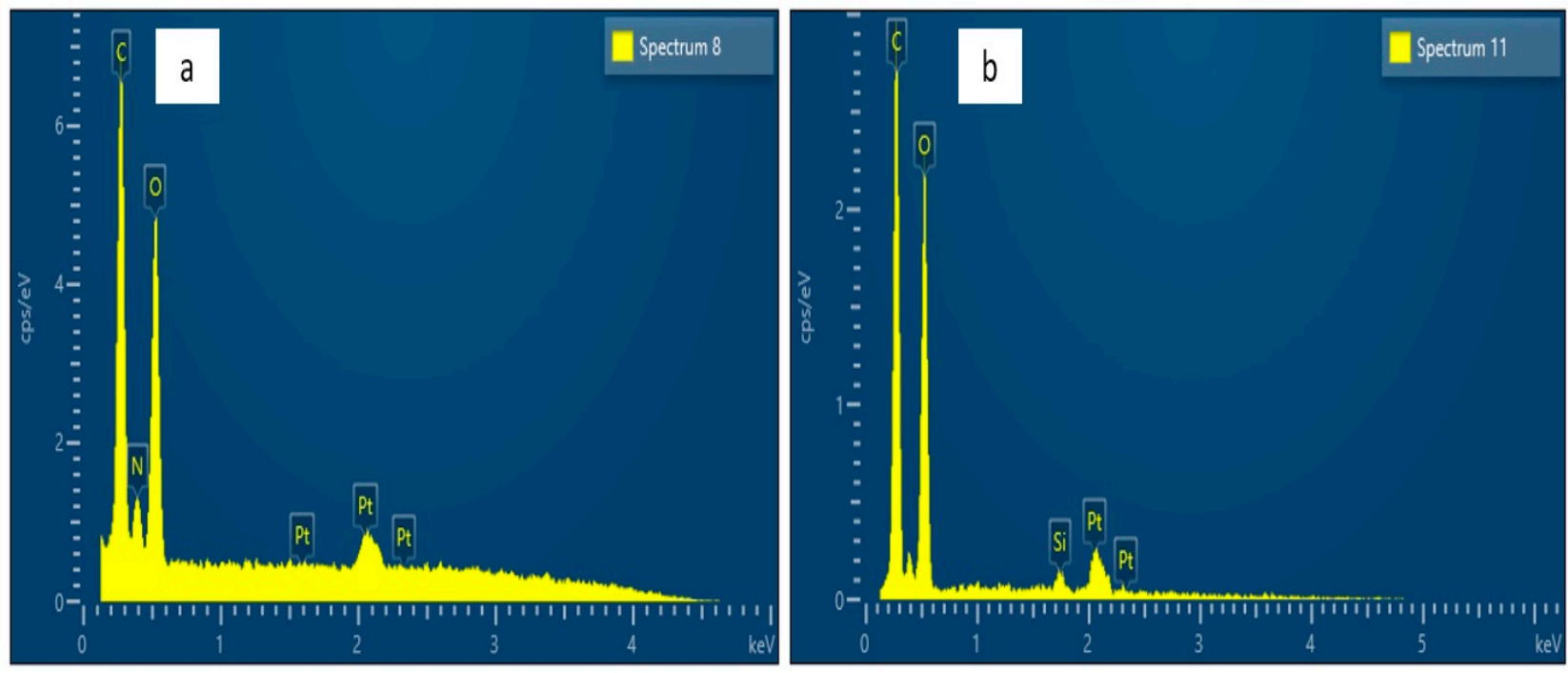

Figure 6. Elemental analysis of the OPF (a) and OPF-S (b).

\subsection{Mechanical Properties}

Generally, the maximum load that samples could support without fracture while being stretched was measured as tensile strength. A modulus of elasticity by dividing the longitudinal stress over strain is known as Young's modulus, while elongation of break determines the cracking resistance of samples upon stretching and changing in shape. The tensile properties of PP, untreated OPF-PP, modify OPF-S-PP and OPF-S-PP-MAgPP and are shown in Figure 7. It was observed that OPF as the reinforcing natural fiber has a significant role in increasing the value of Young's modulus. The presence of silica increases the polarity of the composite from $34.1 \%$ to $35.9 \%$ during the chemical interactions between OPF-S and PP [41]. On the contrary, the elongation of break for all composites were reduce by $5 \%$ to $10 \%$ than the pure PP, while an improvement in tensile strength was observed in the presence of silica sol-gel and MAgPP in the composite structure. The presence of silica at $55 \%$ could reduce the void content in OPF surface, which results in less porosity of the composite structure. The same trends of tensile strength and Young's modulus were also reported by using K-carrageenan-silica composite [42]. Furthermore, the addition of MAgPP as a coupling agent or compatibilizer improves interfacial bonding between natural fiber and PP matrix [43], which enhances the tensile strength of the composite. Hence, it is suggested that OPF-S-PP-MAgPP composite showed the highest toughness and stiffness with values of tensile strength, Young's modulus, and elongation at break of $30.9 \mathrm{MPa}, 881.8 \mathrm{MPa}$, and $15.1 \%$, respectively.

Figure 8 illustrates the flexural properties and impact strength of PP and the examined composites. The flexural strength represents the required amount of force to bend the composite, while flexural modulus is related to the amount of force required to deform the composite. It was noted that high force was required to bend and deform the pure PP as compared to the examined composites. The result suggests that the silica might not be homogeneously spread and agglomerated on the surface of OPF, which would cause low stress transfer and therefore low flexural strength and flexural modulus [23]. Nevertheless, the presence of silica sol-gel in OPF slightly improved the flexural strengths of OPF-S-PP and OPF-S-PP-MAgPP composites at $17.8 \mathrm{MPa}$, compared to the flexural strength of the untreated OPF-PP composite at 16.7 MPa. Furthermore, all samples of OPF-reinforced PP composites displayed low values of impact strength, as compared to PP that has the highest value of impact strength at $6.9 \mathrm{~kJ} / \mathrm{m}^{2}$. The result was due to the natural properties of polar (OPF and silica) and non-polar (PP) materials, which resulted in low tenacity to absorb mechanical energy under impact loading before fracturing. As aforementioned, the inhomogeneous spread of silica would lead to a lack of interfacial adhesion between OPF and OPF-S with PP, rendering the composite samples to be susceptible to fracture under 
the impact loading. Furthermore, the addition of MAgPP resulted in a decrease of impact strength caused by the inability of compatibilizer to improve interfacial adhesion between the reinforcing natural fiber and polymer matrix [44].

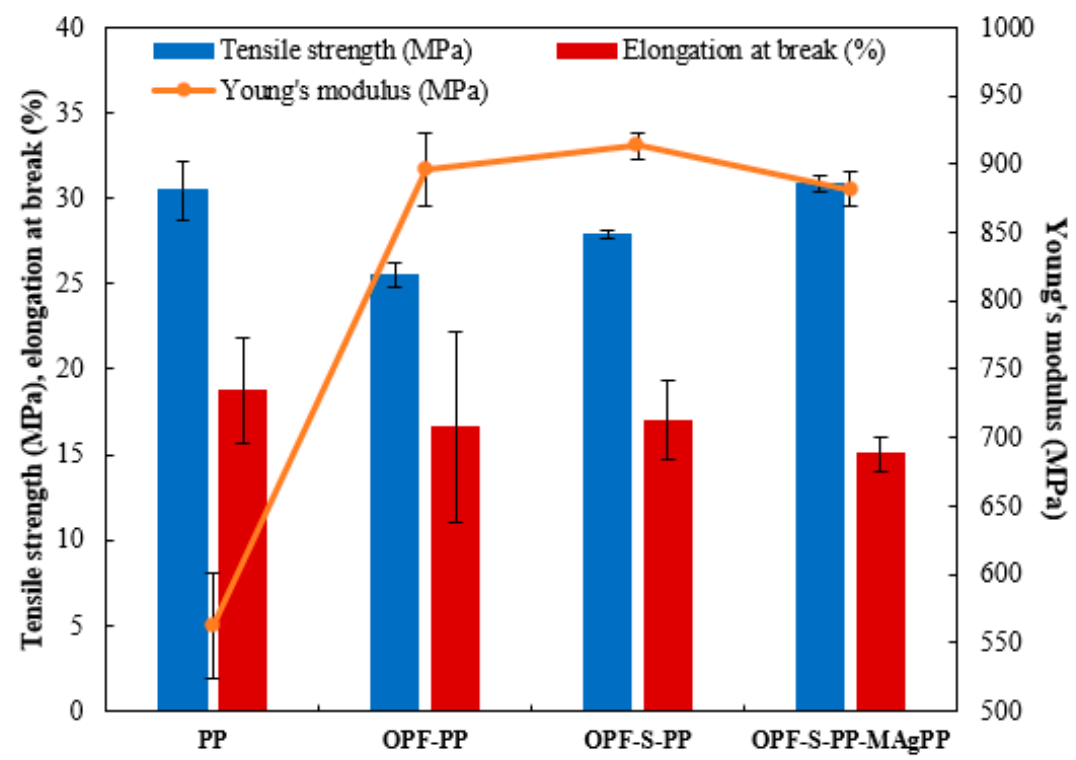

Figure 7. Tensile properties of PP, OPF-PP, S-OPF-PP, and S-OPF-PP-MAgPP composites.

(a)
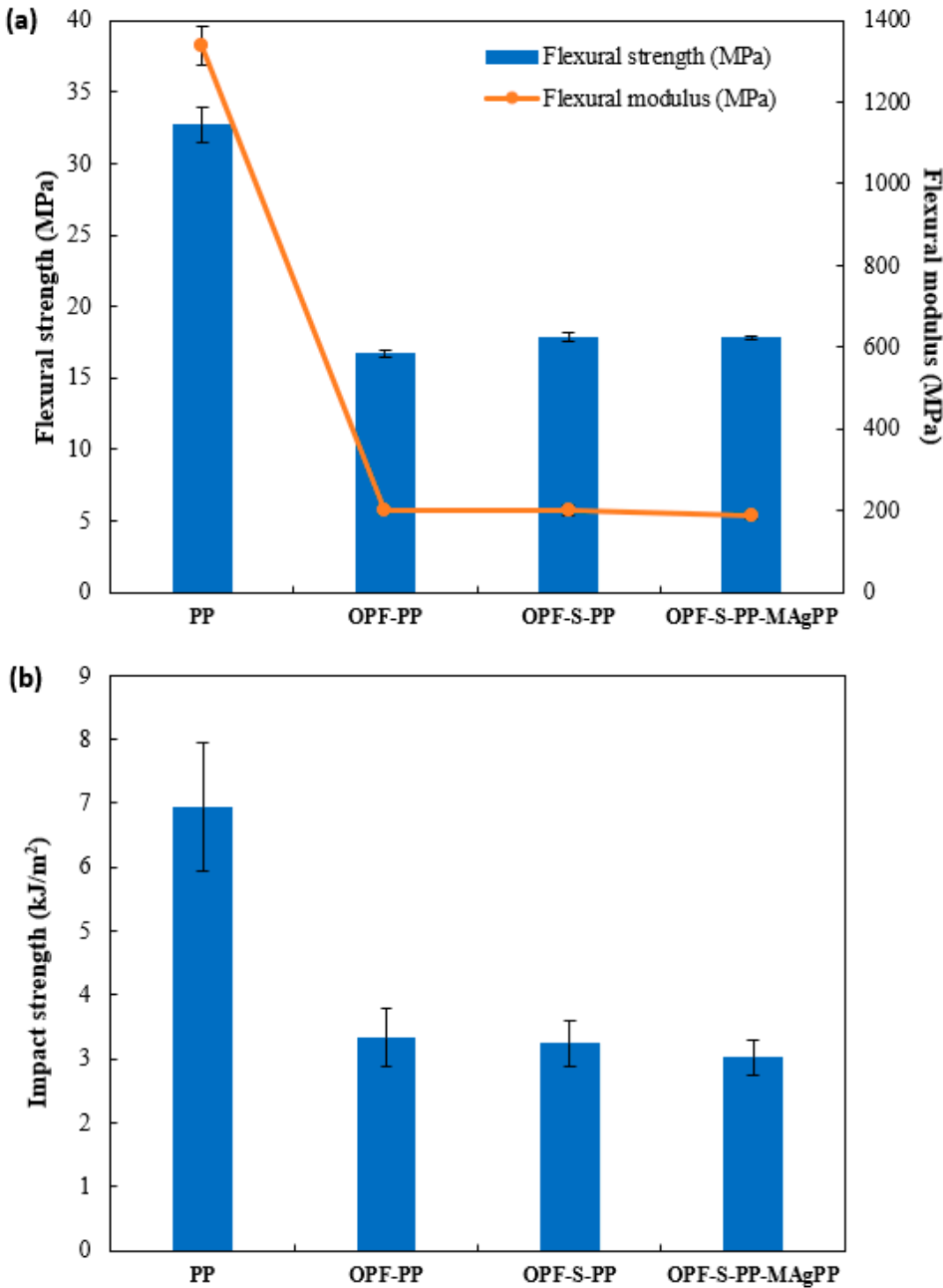

Figure 8. (a) Flexural properties and (b) impact strengths of PP, OPF-PP, OPF-S-PP, and OPF-S-PPMAgPP composites. 


\subsection{Thermal Decomposition Analysis}

Figure 9 presents the TGA curves of different composite formulations. At the first stage, OPF-S-PP and OPF-S-PP-MAgPP specimens thermally degraded at slightly lower temperature than OPF-PP, due to the condensation of $\equiv \mathrm{Si}-\mathrm{OH}$ groups. All composites displayed similar trends of rapid exothermic weight loss at the second stage, which would be the oxidation of carbon functional groups. OPF-S-PP and OPF-S-PP-MAgPP had a weight loss of $30 \%$ at a decomposition temperature of $461{ }^{\circ} \mathrm{C}$ (Table 6), which was $5{ }^{\circ} \mathrm{C}$ higher than OPF-PP. Successful penetration of silica sol-gel into the voids of OPF results in increased stability against thermal decomposition. OPF-S-PP-MAgPP showed the highest inflection point at $477^{\circ} \mathrm{C}$ at the greatest change on the weight loss curve. This indicates the positive effects of the reinforcing OPF, silica sol-gel, and MAgPP coupling agent on thermal resistance. At temperature above $500{ }^{\circ} \mathrm{C}$, the weight residue of OPF-PP approached zero. On the other hand, the weight residue of OPF-S-PP and OPF-S-PP-MAgPP were 5.6 and $5.7 \%$ respectively at decomposition temperature of $1000^{\circ} \mathrm{C}$. The resistance against thermal decomposition could also be contributed by additional heat capacity of silica based on similar observation previously reported [45].

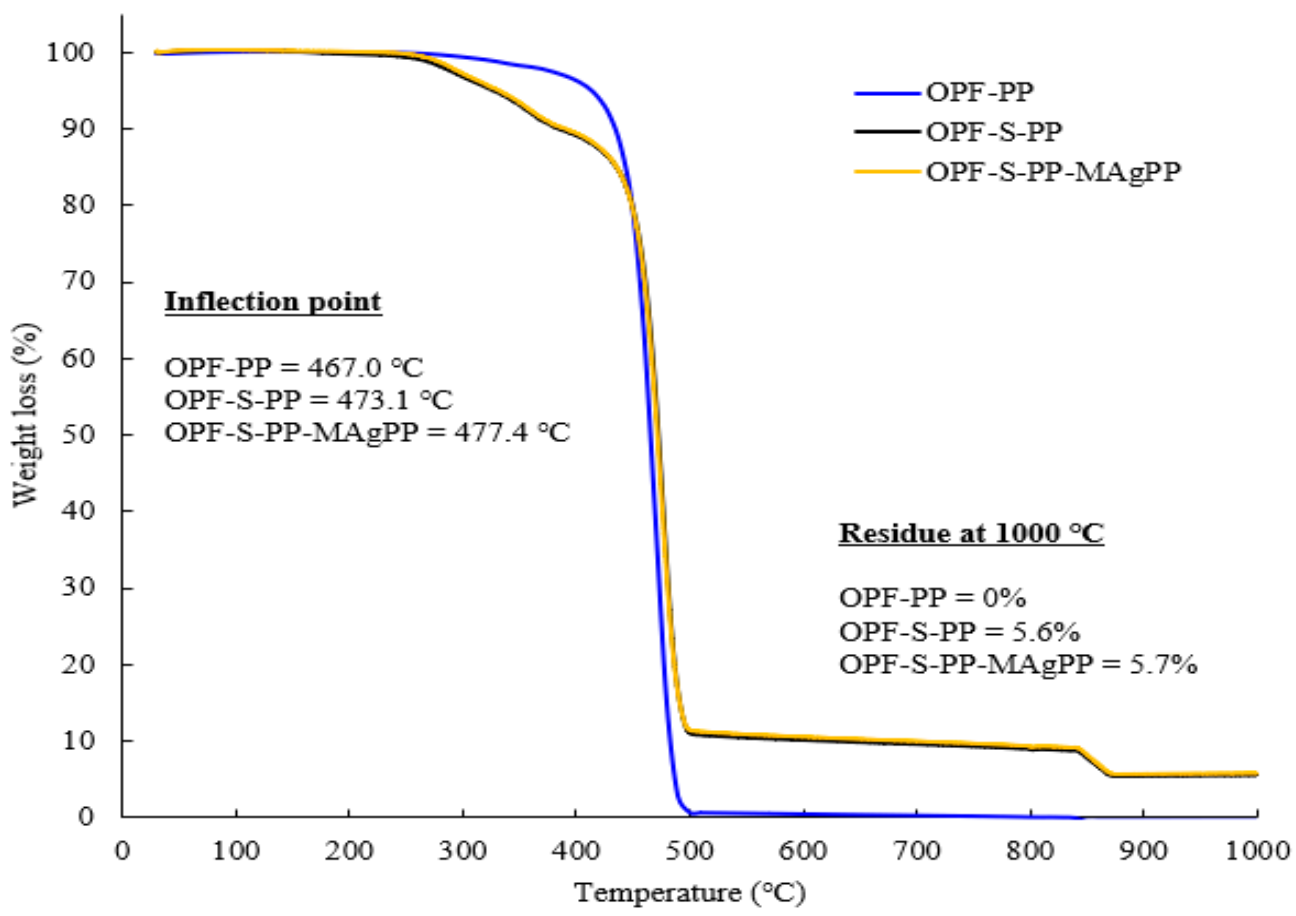

Figure 9. Thermogravimetric curves of OPF-PP, OPF-S-PP, and OPF-S-PP-MAgPP composites.

Table 6. Decomposition temperature of composites at different weight losses from thermogravimetric analysis.

\begin{tabular}{cccccc}
\hline \multirow{2}{*}{ Composite } & \multicolumn{5}{c}{ Decomposition Temperature $\left({ }^{\circ} \mathbf{C}\right)$} \\
\cline { 2 - 5 } & $\mathbf{2 \%}$ & $\mathbf{5 \%}$ & $\mathbf{1 0} \%$ & $\mathbf{2 0} \%$ & $\mathbf{3 0} \%$ \\
\hline OPF-PP & 369.8 & 414.4 & 434.4 & 449.7 & 456.1 \\
OPF-S-PP & 283.0 & 327.3 & 384.8 & 449.7 & 461.4 \\
OPF-S-PP-MAgPP & 288.4 & 331.0 & 389.3 & 449.3 & 460.5 \\
\hline
\end{tabular}

\section{Conclusions}

1. In situ silica sol-gel process on OPF was an effective method to fill the voids of OPF, which enhanced the mechanical and thermal properties of oil palm fiber-reinforced polypropylene composite. 
2. The optimum silica content of $34.1 \%$ and silica residue of $35.9 \%$ were achieved under optimum conditions of $21.3 \mathrm{~h}$ soaking time, 50 min drying time, $\mathrm{pH}$ value of 9.26, and 1:4 molar ratio of TEOS to water. The drying time after in situ silica sol-gel process on OPF was the most significant independent variable on silica content, while silica residue from TGA was highly influenced by molar ratio of TEOS to water.

3. MAgPP was introduced for better interfacial adhesion between OPF-S and PP. The tensile strength of OPF-S-PP-MAgPP was significantly improved at $30.9 \mathrm{MPa}$, but other mechanical properties showed insignificant differences as compared to OPF-S-PP.

4. The OPF-S-PP-MAgPP showed the highest thermal stability with the highest inflection point of $477^{\circ} \mathrm{C}$. However, the degradation difference between OPF-S-PP and OPF-SPP-MAgPP was marginal.

5. The outcomes of this study will be useful for future works on formulations of modified oil palm fiber-reinforced polypropylene composite in many potential applications.

Author Contributions: Conceptualization, N.M.R. and M.Z.; methodology, M.S.H.; software, H.A.H.; validation, N.A.K. and A.N.A.Y.; formal analysis, A.N.S.F.; investigation, M.Y.H.; resources, N.A.; data curation, M.Z.; writing-original draft preparation, N.M.R.; writing-review and editing, M.Z. and M.S.H.; visualization, M.S.H.; supervision, M.Z., project administration, M.Z.; funding acquisition, A.N.A.Y. All authors have read and agreed to the published version of the manuscript.

Funding: Universiti Kuala Lumpur Short Term Research Grant (STRG) Ref: UniKL/CORI/str19036.

Institutional Review Board Statement: Not applicable.

Informed Consent Statement: Not applicable.

Data Availability Statement: Not applicable.

Acknowledgments: The authors gratefully acknowledge the financial support of Universiti Kuala Lumpur Short Term Research Grant (STRG) Ref: UniKL/CORI/str19036. The authors would also like to thank the laboratory technicians of UniKL-MICET for their invaluable assistance.

Conflicts of Interest: The authors declare no conflict of interest.

\section{References}

1. Balla, V.; Kate, K.H.; Satyavolu, J.; Singh, P.; Tadimeti, J.G.D. Additive manufacturing of natural fiber reinforced polymer composites: Processing and prospects. Compos. Part B Eng. 2019, 174, 106956. [CrossRef]

2. Asim, M.; Abdan, K.; Jawaid, M.; Nasir, M.; Dashtizadeh, Z.; Ishak, M.R.; Hoque, M.E. A Review on Pineapple Leaves Fibre and Its Composites. Int. J. Polym. Sci. 2015, 2015, 950567. [CrossRef]

3. Satyanarayana, K.G.; Arizaga, G.G.C.; Wypych, F. Biodegradable composites based on lignocellulosic fibers-An overview. Prog. Polym. Sci. 2009, 34, 982-1021. [CrossRef]

4. Singh, T.J.; Samanta, S. Characterization of Kevlar Fiber and Its Composites: A Review. Mater. Today Proc. 2015, 2, 1381-1387. [CrossRef]

5. Sood, M.; Dwivedi, G. Effect of fiber treatment on flexural properties of natural fiber reinforced composites: A review. Egypt. J. Pet. 2018, 27, 775-783. [CrossRef]

6. Zhang, Z.; Cai, S.; Li, Y.; Wang, Z.; Long, Y.; Yu, T.; Shen, Y. High performances of plant fiber reinforced composites-A new insight from hierarchical microstructures. Compos. Sci. Technol. 2020, 194, 108151. [CrossRef]

7. Shah, D.U. Developing plant fibre composites for structural applications by optimising composite parameters: A critical review. J. Mater. Sci. 2013, 48, 6083-6107. [CrossRef]

8. Ahmad, F.; Choi, H.S.; Park, M.K. A Review: Natural Fiber Composites Selection in View of Mechanical, Light Weight, and Economic Properties. Macromol. Mater. Eng. 2015, 300, 10-24. [CrossRef]

9. Sumathi, S.; Chai, S.; Mohamed, A.R. Utilization of oil palm as a source of renewable energy in Malaysia. Renew. Sustain. Energy Rev. 2008, 12, 2404-2421. [CrossRef]

10. Talero, G.; Rincón, S.; Gómez, A. Biomass torrefaction in a standard retort: A study on oil palm solid residues. Fuel 2019, 244, 366-378. [CrossRef]

11. Abdullah, N.; Sulaiman, N.A.A.F. The Oil Palm Wastes in Malaysia. In Biomass Now-Sustainable Growth and Use; Intech Open: Rijeka, Croatia, 2013; Volume 1, pp. 75-93. [CrossRef]

12. USDA, World Agricultural Production, Circular Series-WAP 5-20. 2020. Available online: https://usda.library.cornell.edu/ concern/publications /5q47rn72z?locale=en (accessed on 14 September 2021). 
13. Huda, M.S.; Drzal, L.T.; Mohanty, A.K.; Misra, M. Chopped glass and recycled newspaper as reinforcement fibers in injection molded poly(lactic acid) (PLA) composites: A comparative study. Compos. Sci. Technol. 2006, 66, 1813-1824. [CrossRef]

14. Fang, T.W.; Malaysia, M.U.S.; Asyikin, N.S.S.N.; Shawkataly, A.K.H.P.; Kassim, M.H.M.; Syakir, M. Water Absorption and Thickness Swelling of Oil Palm Empty Fruit Bunch (OPEFB) and Seaweed Composite for Soil Erosion Mitigation. J. Phys. Sci. 2017, 28, 1-17. [CrossRef]

15. Ramlee, N.A.; Jawaid, M.; Zainudin, E.S.; Yamani, S.A.K. Tensile, physical and morphological properties of oil palm empty fruit bunch/sugarcane bagasse fibre reinforced phenolic hybrid composites. J. Mater. Res. Technol. 2019, 8, 3466-3474. [CrossRef]

16. Gassan, J.; Bledzki, A.K. Thermal degradation of flax and jute fibers. J. Appl. Polym. Sci. 2001, 82, 1417-1422. [CrossRef]

17. Dicker, M.; Duckworth, P.F.; Baker, A.B.; Francois, G.; Hazzard, M.K.; Weaver, P. Green composites: A review of material attributes and complementary applications. Compos. Part A Appl. Sci. Manuf. 2014, 56, 280-289. [CrossRef]

18. Facca, A.G.; Kortschot, M.T.; Yan, N. Predicting the tensile strength of natural fibre reinforced thermoplastics. Compos. Sci. Technol. 2007, 67, 2454-2466. [CrossRef]

19. Pickering, K.L.; Efendy, M.G.A.; Le, T.M. A review of recent developments in natural fibre composites and their mechanical performance. Compos. Part A Appl. Sci. Manuf. 2016, 83, 98-112. [CrossRef]

20. Gurunathan, T.; Mohanty, S.; Nayak, S.K. A review of the recent developments in biocomposites based on natural fibres and their application perspectives. Compos. Part A Appl. Sci. Manuf. 2015, 77, 1-25. [CrossRef]

21. Senthilraja, R.; Sarala, R.; Antony, A.G. Effect of acetylation technique on mechanical behavior and durability of palm fibre vinyl-ester composites. Mater. Today Proc. 2020, 21, 634-637. [CrossRef]

22. Essabir, H.; Boujmal, R.; Bensalah, M.O.; Rodrigue, D.; Bouhfid, R.; Qaiss, A.E.K. Mechanical and thermal properties of hybrid composites: Oil-palm fiber/clay reinforced high density polyethylene. Mech. Mater. 2016, 98, 36-43. [CrossRef]

23. Ramli, R.; Yunus, R.; Beg, M. Effects of fiber loading, fiber type, its mesh sizes, and coupling agent on the properties of oil palm biomass/polypropylene composites. J. Compos. Mater. 2011, 45, 2165-2171. [CrossRef]

24. Jawaid, M.; Khalil, H.A.; Abu Bakar, A.; Khanam, P.N. Chemical resistance, void content and tensile properties of oil palm/jute fibre reinforced polymer hybrid composites. Mater. Des. 2011, 32, 1014-1019. [CrossRef]

25. Faruk, O.; Bledzki, A.K.; Fink, H.-P.; Sain, M. Progress Report on Natural Fiber Reinforced Composites. Macromol. Mater. Eng. 2014, 299, 9-26. [CrossRef]

26. Shinoj, S.; Visvanathan, R.; Panigrahi, S.; Kochubabu, M. Oil palm fiber (OPF) and its composites: A review. Ind. Crops Prod. 2011, 33, 7-22. [CrossRef]

27. Karsli, N.G.; Aytac, A. Effects of maleated polypropylene on the morphology, thermal and mechanical properties of short carbon fiber reinforced polypropylene composites. Mater. Des. 2011, 32, 4069-4073. [CrossRef]

28. Yi, S.; Xu, S.; Li, Y.; Gan, W.; Yi, X.; Liu, W.; Wang, Q.; Wang, H.; Ou, R. Synergistic toughening effects of grafting modification and elastomer-olefin block copolymer addition on the fracture resistance of wood particle/polypropylene/elastomer composites. Mater. Des. 2019, 181, 107918. [CrossRef]

29. Qian, T.; Li, J.; Ma, H.; Yang, J. The preparation of a green shape-stabilized composite phase change material of polyethylene glycol $/ \mathrm{SiO}_{2}$ with enhanced thermal performance based on oil shale ash via temperature-assisted sol-gel method. Sol. Energy Mater. Sol. Cells 2015, 132, 29-39. [CrossRef]

30. He, F.; Wang, X.; Wu, D. New approach for sol-gel synthesis of microencapsulated n-octadecane phase change material with silica wall using sodium silicate precursor. Energy 2014, 67, 223-233. [CrossRef]

31. Wang, C.; Cai, Z.; Wang, T.; Chen, K. Preparation and thermal properties of shape-stabilized 1, 8-octanediol $/ \mathrm{SiO}_{2}$ composites via sol gel methods. Mater. Chem. Phys. 2020, 250, 123041. [CrossRef]

32. Zulkifli, M.; Hossain, S.; Khalil, N.A.; Yahaya, A.N.A.; Yusof, F.A.M.; Hashim, A.S. Preparation and Characterization of Sol-gel Silica-modified Kenaf Bast Microfiber/Polypropylene Composites. BioResources 2017, 13, 1977-1992. Available online: https: / / ojs. cnr.ncsu.edu/index.php/BioRes/article/view /BioRes_13_1_1977_Zulkifli_Sol_gel_Silica_Kenaf_Bast_Composites/5868 (accessed on 14 September 2021). [CrossRef]

33. Yusof, F.; Tajudin, Z.; Ong, S.; Hashim, A. Optimization of Early Stage Hydrolysis of Silica Sol-Gel/Kenaf using Response Surface Methodology. Mater. Today Proc. 2019, 19, 1663-1672. [CrossRef]

34. Agustín-Sáenz, C.; Machado, M.; Tercjak, A. Antireflective mesoporous silica coatings by optimization of water content in acid-catalyzed sol-gel method for application in glass covers of concentrated photovoltaic modules. J. Colloid Interface Sci. 2019, 534, 370-380. [CrossRef] [PubMed]

35. Mishra, A.; Luyt, A. Effect of sol-gel derived nano-silica and organic peroxide on the thermal and mechanical properties of low-density polyethylene/wood flour composites. Polym. Degrad. Stab. 2008, 93, 1-8. [CrossRef]

36. Wu, C.-S.; Liao, H.-T. Modification of biodegradable polylactide by silica and wood flour through a sol-gel process. J. Appl. Polym. Sci. 2008, 109, 2128-2138. [CrossRef]

37. Çok, S.S.; Koç, F.; Balkan, F.; Gizli, N. Revealing the pore characteristics and physicochemical properties of silica ionogels based on different sol-gel drying strategies. J. Solid State Chem. 2019, 278, 120877. [CrossRef]

38. Pouxviel, J.; Boilot, J.; Beloeil, J.; Lallemand, J. NMR study of the sol/gel polymerization. J. Non Cryst. Solids 1987, 89, 345-360. [CrossRef]

39. Engelhardt, G. Silicon-29 NMR of Solid Silicates. In Encyclopedia of Magnetic Resonance; University of California: Los Angeles, CA, USA, 2007. [CrossRef] 
40. Peña, L.F.; Nanayakkara, C.E.; Mallikarjunan, A.; Chandra, H.; Xiao, M.; Lei, X.; Pearlstein, R.M.; Derecskei-Kovacs, A.; Chabal, Y.J. Atomic Layer Deposition of Silicon Dioxide Using Aminosilanes Di-sec-butylaminosilane and Bis(tert-butylamino)silane with Ozone. J. Phys. Chem. C 2016, 120, 10927-10935. [CrossRef]

41. Bajuri, F.; Mazlan, N.; Ishak, M.R.; Imatomi, J. Flexural and Compressive Properties of Hybrid Kenaf/Silica Nanoparticles in Epoxy Composite. Procedia Chem. 2016, 19, 955-960. [CrossRef]

42. Rane, L.R.; Savadekar, N.R.; Kadam, P.G.; Mhaske, S.T. Preparation and Characterization of K-Carrageenan/Nanosilica Biocomposite Film. J. Mater. 2014, 2014, 736271. [CrossRef]

43. Dewi, I.R.; Indrajati, I.N.; Nurhajati, D.W. Effect of compatibilizers on the mechanical and morphological properties of polycarbonate/poly (acrylonitrile-butadiene-styrene) blends. IOP Conf. Ser. Mater. Sci. Eng. 2018, 432, 012039. [CrossRef]

44. Sailaja, R.R.N.; Reddy, A.P.; Chanda, M. Effect of epoxy functionalized compatibilizer on the mechanical properties of low-density polyethylene/plasticized tapioca starch blends. Polym. Int. 2001, 50, 1352-1359. [CrossRef]

45. Selvi, M.; Vengatesan, M.R.; Devaraju, S.; Kumar, M.; Alagar, M. In situ sol-gel synthesis of silica reinforced polybenzoxazine hybrid materials with low surface free energy. RSC Adv. 2014, 4, 8446. [CrossRef] 